\title{
Cultura negra e educação antirracista no currículo escolar: potencialidades do trabalho educativo por meio da literatura
}

\author{
Nivaldo Alexandre de Freitas? \\ Camila Maria Santos de Pinho² \\ Jessica Silva Cantão ${ }^{3}$
}

\section{RESUMO}

Este artigo discute a necessidade de discussões sobre a cultura negra e o racismo na escola e busca fornecer um exemplo de como a literatura pode contribuir para isso de maneira consistente. O texto se divide em três partes. Na primeira, é exposto o longo caminho de interdições a que o negro foi submetido em sua história, como a tentativa de imposição de uma falsa democracia racial, a fragilização econômica e social, a tentativa de apagamento da história com os processos assimilatórios e de embranquecimento. Mas reflete também acerca das várias formas de resistência frente a esse sofrimento, o que inclui a preservação da cultura imaterial. Na segunda parte, a literatura e sua capacidade de expor a realidade são tomadas para pensar um aspecto que pode, no interior da escola, levar à consciência do racismo e a uma situação propícia à identificação com o outro, criando condições para a diversidade e para uma educação de fato inclusiva. $\mathrm{Na}$ terceira parte é analisada uma obra literária especificamente - O mulato, de Aluísio Azevedo - como um exemplo de uma discussão que precisa ser feita na escola, de modo a destacar e combater o racismo que percorre longa data na história brasileira e possui raízes em múltiplas áreas.

Palavras-chave: Racismo, literatura, currículo.

\section{Black culture and antirracist education in the school curriculum: potentialities}

\section{of educational work through literature}

\begin{abstract}
This article addresses the need for debates about black culture and racism in school and aims at providing an example of how literature can consistently contribute to this. The paper is divided into three parts. The first one approaches the long road of

\footnotetext{
1 Psicólogo e Doutor em Psicologia Escolar pela Universidade de São Paulo, Professor adjunto da Universidade Federal de Rondonópolis, Rondonópolis, MT, Brasil. ORCID ID: https://orcid.org/0000-0001-9900-4041.E-mail: nivaldo@ufr.edu.br

2 Psicóloga e Mestre em Educação pela Universidade Federal de Rondonópolis, Rondonópolis, MT, Brasil. ORCID ID: https://orcid.org/0000-0002-9729-5276. E-mail: kamilapinho67@gmail.com

3 Psicóloga graduada pela Universidade Federal de Rondonópolis, Rondonópolis, MT, Brasil. ORCID ID: https://orcid.org/0000-0002-3171-2559. E-mail: jessicacantao@gmail.com
}

Revista Exitus, Santarém/PA, Vol. 10, p. 01-31, e020076, 2020. 
interdictions to which the Negro was subjected in his history, such as the attempt to impose a false racial democracy, the economic and social fragilization, the attempt to erase history through assimilation and whitening. But it also reflects on the various forms of resistance to this suffering, which includes the preservation of immaterial culture. In the second part, literature and its capacity to expose reality are taken to reflect about an aspect that can, within the school, lead to an awareness of racism and a situation conducive to identification with the other, creating conditions for diversity and for inclusive education. In the third part, a literary work is analyzed specifically - O mulato, by Aluísio Azevedo - as an example of a discussion that needs to be done in school in order to highlight and fight against racism that has been going on for a long time in Brazilian history and has roots in multiple areas.

Keywords: Racism, literature, curriculum.

\section{Cultura negra y educación antirracista en el currículo escolar: potencialidades del trabajo educativo por medio de la literatura}

\section{RESUMEN}

Este artículo tiene como objetivo discutir cuál es la importancia y la relación entre la cultura negra y el racismo en la escuela; así como analizar un ejemplo de cómo la literatura puede contribuir al debate. El artículo se divide en tres partes. En la primera parte, se expone el largo camino de interdicciones a que el negro fue sometido en su historia como la imposición de una falsa democracia racial, la fragilización económica y social, el intento de borrar de la historia con los procesos asimilatorios y de blanqueamiento. También discute sobre las diversas formas de resistencia frente a ese sufrimiento, lo que incluye la preservación de la cultura inmaterial. En la segunda parte, la literatura y su capacidad de exponer la realidade, son utilizadas para pensar un aspecto que puede, dentro de la escuela, llevar a la conciencia del racismo y a una situación propicia para la identificación con el outro y crear condiciones para la diversidad y para una educación inclusiva. Finalmente, en la tercera parte, se analiza una obra literaria específica: O mulato, de Aluísio Azevedo, como un ejemplo para discutir, destacar y combatir el racismo en la historia brasileña y que tiene raíces en múltiples áreas.

Palabras clave: Racismo, literatura, currículo.

\section{Introdução}

A Lei no 10.639 de 2003 tornou obrigatória a presença da cultura africana e afro-brasileira no currículo da educação básica e do ensino superior, a fim de promover uma educação antirracista. Com isso, a história e a cultura africana e afro-brasileira se tornam temáticas que percorrem todos os componentes curriculares no âmbito escolar. A partir dessa importante conquista, abriu-se a possibilidade de a cultura negra estar presente na 
escola, bem como o sofrimento do povo negro, gravado nos corpos e nas subjetividades ao longo de séculos de sistemática opressão. Todavia, podese pensar como essa lei pode se efetivar, realizando seu desígnio, pois muitas vezes o que se vê é a presença superficial das temáticas da cultura negra, de caráter quase folclórico, e que não perfaz substância para uma educação antirracista. Isso se deve a vários fatores, entre eles o entendimento reduzido do racismo e suas consequências e a pouca disposição em enfrentar a ferida aberta do racismo na sociedade brasileira, pois, para enfrentá-lo, é preciso pensar efetivamente nos conteúdos curriculares a serem trabalhados e buscar a compreensão acerca de como eles podem ser mobilizados para uma discussão sobre a cultura negra.

Este artigo pretende mostrar não apenas como o racismo se dá de forma incisiva, mas também como ele pode ser combatido por uma educação antirracista comprometida com a ideia de inclusão, o que abarca a mobilização de certos conteúdos, como os da história, da geografia e da literatura, por exemplo, com vistas a discutir, efetivamente, a cultura negra e o racismo.

É preciso atuar na escola contra o silenciamento da história do negro, resgatando sua história encoberta. O racismo impede a harmonia social e o desenvolvimento sustentável de uma sociedade democrática. Uma educação para a convivência precisa se ocupar com isso.

Muitos, porém, silenciam sobre o racismo encoberto e mesmo sobre o explícito, imaginando que não seria um assunto que lhes coubesse:

[...] como a professora que vê e ouve um aluno discriminando outro e não age em defesa do discriminado, dando a entender que aquilo não é com ela. Mas é com ela, sim! Educar inclui preparar para uma convivência harmônica. A prática do racismo desagrega a sociedade e impede seu potencial humano de se manifestar plenamente. E o país precisa de coesão para ter equilíbrio social e prosperidade sustentável. Entretanto, no cotidiano competitivo, quem está preocupado com isso? (CUTI, 2017, p. 199).

Um erro primário é pensar que apenas o negro se beneficia do fim do preconceito racial e de sua cultura e história vividas em meio a essa sociedade. 
Este artigo está estruturado em três partes. Na primeira delas, as várias interdições a que o negro foi submetido em sua história, são destacadas de modo a expor as raízes do racismo brasileiro, como a tentativa de imposição de uma falsa democracia racial, a fragilização econômica e social, a tentativa de apagamento da história com os processos assimilatórios e de embranquecimento. Também busca refletir acerca das várias formas de resistência frente a esse sofrimento, o que inclui a preservação da cultura imaterial. Na segunda parte, a literatura e sua capacidade de expor a realidade são tomados para pensar um aspecto que pode levar à consciência do racismo e a uma situação propícia à identificação com o outro, criando condições para a diversidade e para uma educação de fato inclusiva. Por fim, na última parte, é analisado O mulato, de Aluísio Azevedo, como um exemplo de uma discussão a ser feita na escola, de modo a destacar e combater o racismo que percorre longa data na história brasileira e possui raízes em múltiplas áreas.

\section{Arte e epistemologias pretas}

A formação educacional do homem negro e da mulher negra no Brasil é marcada pela palavra 'ausência', o que se perpetua historicamente até hoje. Ausência de referências, ausência de cor, ausência de intelectuais, ausência de atores e atrizes negros, salvo em papéis subalternos. Nas ciências, encontrar referências a autores e autoras pretos é quase que impossivel, quando não estão colocados no campo do fetichismo ou enquanto recorte: "Quando se fala na emocionalidade do negro é quase sempre para the contrapor a capacidade de raciocínio do branco" (SANTOS, 1983, p. 30). Essa ausência se configura sobre o corpo de tal forma que forja uma subjetividade que se expressa a partir dos ditames das normas estabelecidas historicamente na cultura, normas essas que ainda são definidas por uma moral e uma ética universalista de base eurocêntrica, patriarcal e capitalista. Segundo Bonfim (2009, p. 242): "O princípio simbólico dos traços fenotípicos, notadamente a cor da pele, catalisa a eficácia de 
uma propriedade distintiva, pois anuncia visualmente a diferença. É a cor da pele o maior princípio simbólico de dominação racial na sociedade brasileira".

Frente a isso, ao observar como as escolas são pensadas atualmente, os resquícios estão presentes de maneira não tão sutil. A arte disciplinar pode ser entendida enquanto uma ferramenta de domínio sobre o corpo, orientada por um modelo de cidadania que coopera para compreender que esse modelo de instituição educacional, ao operar sobre o corpo, opera na extensão da vida. A conservação de modelos de punição, vigilância e hierarquias do saber é construída historicamente e mantém a escola sob a influência desse 'sistema'. Essa perspectiva abrange as relações, como as categorias etárias, principalmente com as crianças e os jovens, ao imputar a essa 'fase' da vida uma massificação que cristaliza a produção de sentidos sob uma única perspectiva. A linha do controle e produção de um corpo único e adequado a essa lógica conserva costumes semelhantes ao regime militar; reserva-se aos dissidentes, aos rebeldes, uma detenção não apenas no sentido burocrático, mas perfeitamente aplicável ao corpo:

Determinando lugares individuais tornou possível o controle de cada um e o trabalho simultâneo de todos. Organizou uma nova economia do tempo de aprendizagem. Fez funcionar o espaço escolar como uma máquina de ensinar, mas também de vigiar, de hierarquizar, de recompensar (FOUCAULT, 1987, p. 173).

Porém, é neste caminho de interdições que são construídas as resistências e isso não é uma invenção moderna, mas composição da história dos povos negros no continente e na diáspora há mais de 300 anos. Olhar para a história dos negros e dos povos originários no contexto brasileiro ganha força, os atos de resistência e sobrevivência sendo "[...] a visão quilombola, que traz a memória e a atitude de quem resistiu à assimilação forçada dos negros escravizados na Colônia e no Império e dos negros libertos na República racista" (SANTOS, 2015, p. 11). Sintetizando anos de história e proposições de análise, um ponto crucial da obstinação dos negros pelos valores e princípios africanos em território brasileiro foi a luta contra a constituição de uma falsa democracia racial, em que se tira o foco da 
espoliação dos conhecimentos africanos que os negros e negras deste país preservavam (NASCIMENTO, 2017).

O caminho que é apresentado aqui, de violência histórica e material, foi perpetrado sob as condições de uma visão racista sustentada no debate científico e jurídico. Desta forma, essas questões passam a constituir vários âmbitos da experiência de sociabilidade, como o aspecto econômico desses povos, que passa por uma fragilização, o aspecto subjetivo, que se condiciona por forças externas que não contribuem para auto imagem, os aspectos espirituais, sendo a religiosidade um fator de estratégia militar para docilizar os povos sequestrados para as colônias. Essa é uma realidade que se abateu sobre a conjuntura familiar e cultural dos povos africanos do continente e da diáspora. Um saqueamento baseado no processo que correlacionava o sujo e impuro a esses povos. Ainda nessa perspectiva:

O objetivo não expresso dessa ideologia é negar ao negro a possibilidade de autodefinição, subtraindo-lhe os meios de identificação racial. Embora na realidade social o negro seja discriminado exatamente por causa de sua condição racial e da cor, negam a ele, com fundamentos na lei, o direito legal de autodefesa (NASCIMENTO, 2017, p. 94).

Todavia, essa produção de resistências é uma materialidade forte para conservar e proteger não só a condição de sobrevivência, mas a produção material e intelectual de um povo. Neste sentido, observa-se crescer o debate por uma pluralidade epistemológica que construa uma descolonização do pensamento, dos modos de produção de vida e socialização. Entrando para o campo da arte, o resgate histórico conduz para essa vertente de análise e apresenta fatos que mostram como a manifestação artística, o cenário dos museus, dos palcos e da literatura evidenciam a espoliação da cultura africana e o local do negro numa perspectiva fetichista e de segunda categoria. A emocionalidade do negro recebe uma representação bastante problemática:

O 'privilégio da sensibilidade' que se materializa na musicalidade e ritmicidade do negro, a singular resistência física e extraordinária potência e desempenho sexuais são atributos que revelam um falso reconhecimento de uma suposta superioridade negra. Todos estes 
'dons' estão associados à 'irracionalidade' e 'primitivismo' do negro em oposição à 'racionalidade' e 'refinamento' do branco. Quando se fala na emocionalidade do negro é quase sempre para the contrapor a capacidade de raciocínio do branco (SANTOS, 1983, p. 30).

Para ilustrar que esse fato histórico se repete pelo mundo e não apenas na realidade brasileira, observa-se, na experiência cubana, os ataques à prática do voodo e como essa prática foi estrategicamente organizada para resistir e construir uma unidade negra; no cenário haitiano há o empreendimento da sabedoria a respeito das ervas e dos batuques enquanto estratégias de resistência e sobrevivência (LARKIN, 2009). Apesar das diferenças nos contextos, há uma unidade de ações que são similares entre si. Pode-se ainda citar como exemplo a experiência do Jazz nos Estados Unidos e a Capoeira no Brasil: são materialidades estéticas diferentes que possuem origem nas matrizes africanas de sensibilidade e construção do mundo, que foram marginalizadas e criminalizadas, tornando-se evidências de um processo genocida da manifestação da cultura negra (NASCIMENTO, 1961).

A compreensão de que arte é um espaço da expressão da criatividade e do engajamento subjetivo a respeito das percepções do sujeito na sua relação com o mundo é um prelúdio para a análise de como os processos assimilatórios e de embraquecimento dos espaços negros vertem sobre sua corporeidade e identificação. Pontualmente, para um melhor entendimento, a história da escravidão está posta em uma relação de interdições sobre o corpo dos homens e mulheres negros, alinhando-se, assim, a um contexto que se repetia em outros países e que já delineava os locais reservados a eles: "Africanos escravizados nas Américas viviam em condições que Ihes impossibilitam escrever e publicar grande número de obras. Aprender a ler e escrever era um ato subversivo, proibido por lei" (FINCH III; LARKIN, 2009, p. 42).

Na perspectiva da educação, a oportunidade de as crianças e jovens negras discutirem narrativas positivas a respeito de sua história gera, no campo simbólico e no campo material, uma construção significativa da 
subjetividade. Segundo Santos (1983, p. 17): "Uma das formas de exercer autonomia é possuir um discurso sobre si mesmo. Discurso que se faz muito mais significativo quanto mais fundamentado no conhecimento concreto da realidade". Nessa concepção, a educação é encarada enquanto o local em que as crianças e jovens socializam suas narrativas. É por esse motivo que pensar uma educação negra é fundamental para se pensar o modelo de educação para toda a sociedade. Entende-se que a escola apenas terá espaço para essas discussões se for concebida como plural e dinâmica: "Enquanto desempenho de humanidade, viver é agir. Agir não é ser empurrado pelas circunstâncias; agir é escolher, é decidir." (FÉTIZON, 2002, p. 234). A base de uma educação plural que proporcione uma reflexão sobre a vida e sua história consegue efetivamente promover um local seguro para se pensar a socialização.

É neste sentido que dispositivos como a arte, em suas manifestações, conseguem ampliar os estados do sensível e dos sentidos, sendo que, no ambiente educacional, há uma potência de um educar para a sensibilidade que é transformador de realidades, pois a "[...] aposta na escolha é o reconhecimento de que a educação pode valorizar o que é da ordem do ínfimo, do pequeno, da referência pessoal, da conversação, da diversão, do fortuito" (ALMEIDA, 2010, p. 61). Todavia, pode-se aprofundar um pouco essa concepção de educação e considerar, como um exemplo, a imagem do artífice que em suas mãos detém a prata. Ele vai refinar este material, ampliar e testar toda a sua possibilidade e potência de ser um adorno refinado que se molda a partir da experiência do artesão. Mas esse conhecimento se transmite a partir de uma experiência interligada à sua história e à sua relação com o material. Quando se está diante dos currículos educacionais e das referências de relações humanas enquanto potência de mudança, esbarra-se na incongruência do material do artífice.

Esse material não é meramente o livro didático ou o dia de comemorar a Consciência Negra e organizar os pratos "típicos" africanos, uma prática observável nas escolas há muito tempo. Trata-se, pois, de algo anterior a isso. A incongruência está na composição epistemológica, 
ontológica e cultural desses materiais e técnicas que se usa para educar. Neste sentido, um material que não atende à potencialidade do sujeito enquanto histórico, cultural e espiritualizado é como um estado de ausências que vai construir a subjetividade; um sujeito que não compreende sua história a partir de uma leitura crítica, sistematizada e contínua do mundo, perde oportunidades de gestão autônoma de sua vida individual e coletiva. Segundo Nobles (2009, p. 282): "Ser humano, na visão banto-congo, é ser uma 'pessoa' que é um sol vivo, possuindo um espírito (essência) cognoscente e cognoscível por meio do qual se tem uma relação duradoura com o universo total, perceptível e ponderável". Entretanto, o mesmo autor sustenta que a psique dos africanos do continente e da diáspora passou por um processo de esquecimento de suas raízes e de seu senso de pertença. Seria necessário um retorno para entender a si e construir a partir disso, o que é denominado aqui como 'subjetividade positiva e saudável':

[...] voltar atrás e reconstruir o que esquecemos. Eu diria que o que nós, coletivamente, esquecemos ou, de modo mais preciso, o que nosso opressor tentou esvaziar de nossa mente foi o significado de ser africano. Também acredito que, embora tenha sido pavoroso o ataque contra o senso de ser dos africanos, ele não conseguiu destruir o africano dentro de nós. Entretanto, alterou-se a percepção ou crença em nosso senso de africanidade intrínseco; e esse senso alterado de consciência é o problema fundamental dos africanos e dos afro-americanos diaspóricos (NOBLES, 2009, p. 277).

Ainda hoje pensa-se que "Para articular uma cultura política afirmativa, verificava-se a importância dos valores africanos de referência e identidade; para recuperar e articulá-los, seria necessária uma orientação afrocentrada na pesquisa e no pensamento" (FINCH III; LARKIN, 2009, p.55). Assim, é possível afirmar que o resgate de figuras intelectuais e referências negras é que inicia a pauta dessa discussão para um currículo educacional comprometido, escurecendo os debates. Também é preciso colocar em análise crítica autores e autoras, tanto no âmbito da saúde, como nos âmbitos da educação e da arte, que sustentaram essas epistemologias higienistas e segregacionistas e que são perpetuadas nos currículos 
educacionais. A aposta em educação antirracista deve ser concebida em uma episteme que abarca essas noções. Ao considerar que a escola é um espaço de construção biopolítica articulada à construção democrática, é imprescindível problematizar essas bases para que se conserve o direito e autonomia das crianças negras e efetivamente se tenha uma educação:

[...] que considere não só o envolvimento intelectual dos educandos mas também o envolvimento de sua sensibilidade, o que pode gerar uma participação efetiva pois dotada do sentimento de pertença, imprescindível de toda convivência e educação (FERREIRA-SANTOS; ALMEIDA, 2014, p. 173).

Neste sentido, a cultura e as materialidades estéticas também estão passíveis da mesma atuação. Extrair o máximo dessas potencialidades são ações práticas que podem ser desenvolvidas nos currículos educacionais, nas metodologias aplicadas e demais aspectos. E as contribuições desse caminho tornam-se efetivas a partir da quebra de representações subjetivas do sujeito negro para uma novidade da construção de si. E essa articulação é possível a partir de um resgate das produções e ascensão dos materiais mais modernos:

Consiste em ações de descolonização, como se pode dizer, a história da arte, dos museus e do teatro. Mas enquanto artes, museus e teatros foram codificados no Ocidente, em sua própria formação como civilização ocidental, e como tal eles estavam envolvidos, conscientemente ou não, com os projetos imperial-coloniais. A descolonização estética é uma das muitas maneiras de desmontar essa montagem e construir subjetividades descoloniais. A estética descolonial é deslocada pela estética imperial, agora sujeita ao mercado e aos valores corporativos (MIGNOLO, 2010, p. 24).

A partir dessas reflexões se retoma algumas experiências que conduzem a essa transformação no campo da educação, como a publicação da Lei no 10.639 de 2003, que ordena oficialmente não apenas um dispositivo de reparação histórica, o ensino da história e da cultura africana e afro-brasileira nas escolas, mas contribui também para fortalecer um espaço de construção positiva de subjetividades de crianças e adolescentes negros, já que alinha a formação subjetiva e de sociabilidades no contexto educativo (NOGUERA, 2014). A ampliação desse debate nas escolas não consiste apenas em enfatizar certa concepção histórica, mas se 
localiza também no entendimento dos processos de violência, de segregação e de construção de sentidos. É importante compreender que esse é um trabalho do âmbito da construção dos espaços de criatividade e da formação de professores, atrelado à construção de um currículo que abarque essas epistemologias e cosmovisões. Objetiva-se um campo aberto para discutir violências e ressignificações com todas as crianças, sejam elas brancas ou negras, pois a exemplo da arte:

A arte dos povos negros na diáspora objetifica o mundo que os rodeia, fornecendo-lhes uma imagem crítica desse mundo. E assim essa arte preenche uma necessidade de total relevância: a de criticamente historicizar as estruturas de dominação, violência e opressão, características da civilização ocidental-capitalista. Nossa arte negra é aquela comprometida na luta pela humanização da existência humana (NASCIMENTO, 2017, p. 204).

Para a presente análise consideram-se as narrativas de sensibilidades e construções históricas a partir da perspectiva de um currículo que encaminhe as perspectivas e contribuições do pensamento de intelectuais e artistas negros, bem como representações do negro no campo da ciência em livros didáticos e paradidáticos. Este é um caminho teórico metodológico que possibilita a construção de um ideal narrativo que consolida historicamente os povos negros em sua rica dimensão simbólica e cultural: [...] um posicionamento consciente da necessidade de localizar os fenômenos e de promover a agência que se traduzem nas mais variadas formas de resistência à aniquilação psicológica, cultural, política e econômica dos povos africanos (NOGUERA, 2010, p. 5).

A história da construção subjetiva a partir da dimensão cultural é atravessada pelo dicotômico jogo de resistências versus violências, sendo que, ao se analisar a produção artística na história brasileira, não se deve fazer apenas um resgate histórico, mas procurar "[...] incorporar à expressão tradicional africana novas formas, novos espaços e volumes, e outras aquisições técnicas e culturais válidas ao desenvolvimento da arte africana no seu atual ritmo de contemporaneidade" (NASCIMENTO, 1961, p.204).

No tocante à discussão sobre como efetivamente garantir uma escola igualitária e transformadora, há muitos e bons pesquisadores e pesquisadoras 
brasileiras que vêm atuando com um olhar sensível e um ouvir aguçado para outras epistemologias e saberes e que têm contribuições importantes para refletir o educar de maneira comprometida e horizontal (NOGUERA, 2014; RIBEIRO, 2017). Entender que a instituição escolar se submeteu historicamente a relações de poder que não podem ser delimitadas apenas como uma força produtora do bem e do mal é tratar as questões a partir da possibilidade de um olhar de vários ângulos. E essa visão amplia o modo de olhar o corpo, como se desenvolve, como é potente, e amplia para uma coletividade potencializadora dos outros, que quebra com essa tradição da negação e da ausência. Entretanto, as forças materiais que operam pulverizadas nas microrrelações, como referenda o filósofo Michel Foucault (1987), são combatíveis com o esforço no campo prático da escola, nas relações do coletivo e suas decisões.

Seguir este caminho, seja nos currículos educacionais ou em outros espaços, é pleitear não uma cristalização de saberes, mas sua ampliação, e significa romper com os efeitos do modelo de educação eurocêntrico que teve por proposta em seu cerne "[...] a desintegração de outras heranças ancestrais. Diferentes agendas sugerem a solidariedade e a autodeterminação das famílias étnicas, ou a democracia étnica e cultural, como uma direção mais desejável" (HILLIARD III, 2009, p. 317). Um saber ancestral resgatado - vinculado à identidade do negro e suas questões históricas - vai gerar uma nova vida e outros conflitos, evidentemente. A luta pela educação que resgate essas bases epistemológicas para os povos afrobrasileiros é uma estratégia que visa afirmar os modos já existentes de se organizarem a vida e os espaços, além de se produzirem novas vidas e novas socializações.

\section{Literatura e educação inclusiva}

Com as lutas históricas de muitos educadores por uma educação que seja efetivamente inclusiva, a partir das últimas décadas do século XX, houve algumas conquistas importantes em termos de legislações, que tentam 
impulsionar as escolas a reverem seus métodos de ensino discriminatórios para assegurar ao educando o direito de participar de um ambiente sem nenhum tipo de discriminação. Trata-se de um movimento que busca suscitar na escola as condições para a existência de uma sociedade de fato democrática; por isso, ele vai além da ação pedagógica, sendo também política, cultural e social (FLEITH, 2011).

Faz parte da luta por educação inclusiva que as diferenças em sala de aula tenham a atenção da escola. Trata-se de um modelo de educação revolucionário para o Brasil. Geralmente, até mesmo entre os professores, entende-se a educação inclusiva como um modelo que inclui apenas as pessoas com deficiência (o que não seria pouco) talvez por enorme comodismo de se pensar na inclusão de fato da diferença, em um modelo de educação baseado na convivência e não na competição.

O país vive hoje uma transição de uma educação segregante para uma inclusiva, transição que pode ser lenta se não houver engajamento e persistência de variados setores da sociedade que lutam por reconhecimento. Nesse sentido, no que tange o racismo, é fundamental fazer uma discussão na escola acerca do racismo explícito e o encoberto, já que os negros perfazem metade da população brasileira (IBGE, 2018). Discutir, por exemplo, as vantagens e desvantagens do uso de certas expressões passa a ser um recurso importante, como as palavras negro e afrodescendente. Segundo Cuti (2017), a expressão afrodescendente mascara o racismo. As expressões formadas a partir de "afro" trariam certo "conforto" para quem a usa, sem precisar confrontar-se com as ideias racistas, negando-Ihe a existência, diferente da palavra negro, que, se antes era palavra negativa usada pelos racistas com tom ofensivo, foi apropriada de modo positivo para marcar uma identidade e lutar por cidadania. Já para outros, a expressão afrodescendente daria acento à história da cultura negra, às raízes africanas. A discussão na escola sobre essa questão seria uma maneira de abrir a ferida impingida pela violência do racismo e colocar negros e brancos em torno de um tema que precisa ser discutido para que, 
um dia, possa existir convivência não violenta entre os membros dessa sociedade.

A educação inclusiva é um movimento instituinte à medida que refuta a educação baseada na lógica da competição e enseja uma educação cujo fim é a convivência humana. Adorno (2000) aponta que a finalidade da educação deveria ser a não repetição da barbárie que os campos de concentração representaram. Sabe-se que a injustiça e a violência, porém, não cessaram na maior parte do mundo. Especificamente a população negra tem sido exterminada sistematicamente nos guetos da periferia do capitalismo. Mas é difícil pensar outra maneira de o racismo deixar de prosperar - ao menos pensando na esfera subjetiva, enquanto as contradições objetivas persistem - que não seja pela educação, pois, como já dizia Adorno (2000), ela propicia formar desde cedo sujeitos capazes de identificação com o outro.

Freud também apontava a existência da alteridade na identidade, ou seja, o sujeito que passava por experiências capazes de promover a identificação com o outro tinha seu eu constituído com a riqueza da diversidade, trazendo muitos outros sujeitos junto ao seu eu. O eu carrega consigo varias identificações (FREUD, 2011).

Nesse sentido, a escola inclusiva precisa propiciar situações em que a identificação com o outro seja possível. Pode-se pensar, na esteira do que este artigo vem apresentando, que a literatura é um âmbito rico para essa finalidade. Para a análise que importa aqui, a literatura é tomada como um dos vários elementos possíveis de que a escola pode se valer para propiciar a experiência da identificação, bem como a crítica da realidade, aspectos importantes para o combate ao racismo. A obra de arte literária é uma espécie de documento histórico da humanidade que guarda a possibilidade de ricas e variadas experiências formativas. O currículo que o negro deseja, porque se alinha à educação antirracista, precisa acolher a discussão crítica e aprofundada da literatura, tanto a que traz o racismo ocultado ou explícito, para que seja analisado e amplamente debatido, quanto a 
produzida pelo negro, que traz sua história, sua cultura e propicia uma experiência capaz de promover a identificação com o outro.

Acompanhando ainda as reflexões de Adorno acerca da arte, ele aponta que ela, em contato com a realidade, consegue revelar algo dela e do próprio sujeito que o ajuda a libertar-se das amarras de sua alienação: "[...] as obras de arte são cópias do vivente empírico, na medida em que a este fornecem o que the é recusado no exterior e assim libertam daquilo para que as orienta a experiência externa coisificante" (ADORNO, 1970, p.119). A arte é uma cópia da realidade, mas que contém o que é negado ao humano, como a experiência do receptor em sentir-se como algo além de mero objeto do sistema econômico, já que ela obriga a fazer uso das funções humanas, como atenção, imaginação, memória. As obras estão vivas e elas fazem viver quem as procura, pois é por meio do trabalho de toda a sociedade que ela foi possível. Por isso a obra nega o mundo quando é preciso negar e o afirma quando isso faz jus ao sofrimento humano. Adorno explica que a obra expõe a realidade sendo diferente dela:

Que as obras de arte, como mônadas sem janelas, "representem" o que elas próprias não são, só se pode compreender pelo fato de que sua dinâmica própria, a sua historicidade imanente enquanto dialética da natureza e do domínio da natureza não é da mesma essência que a dialética exterior, mas se lhe assemelha em si, sem a imitar (ADORNO, 1970, p. 16).

As literaturas clássica e a contemporânea podem apresentar a cultura e o sofrimento negro de forma a expor o real como um documento histórico, o que é importante ao pensar que a história negra tem sido vítima de um esforço de soterramento. Com isso, a literatura permite destacar os vários elementos históricos que compõem o racismo brasileiro e fornecer subsídios para combatê-lo. Todavia, se a arte no Brasil apresenta as condições para essa crítica, a escola ainda não se apresenta como um âmbito que suscita a sua discussão:

O conhecimento produzido sobre as questões atinentes às relações raciais já é considerável. Entretanto, a formação escolar e acadêmica dos produtores de arte ainda não contempla esse saber, deixando seus formandos quase sempre sem 0 instrumento 
necessário para abordar as relações inter-raciais no que têm de humano e profundo. Subterfugir a respeito do assunto é a lição que a escola nos ensina (CUTI, 2017, p.209).

Há clássicos a serem discutidos e há obras contemporâneas que refletem criticamente sobre o racismo, bem como há produções atuais que, no tocante às relações étnico-raciais, são alienadas: estudam a cultura, mas se esquecem do racismo (CUTI, 2017, p. 206).

Se o racismo for apenas apresentado, mas não discutido de maneira aprofundada e crítica, a passagem pela obra literária terá sido em vão, pois:

O racismo tem história e complexidade humana. Se não for considerado sob esse prisma, torna-se guirlanda, enfeitezinho, só para dizer que o assunto não foi esquecido, ou surge como gemidos críticos. Outra coisa: racismo não é só tema de negro. Os brancos estão envolvidos até o mais recôndito da alma (CUTI, 2017, p. 209).

A escola precisa revolucionar-se e tornar-se âmbito das discussões fundamentais para tornar a convivência social entre diferentes algo possível nesse país:

Há, no tocante aos valores culturais hegemônicos, muita coisa que precisa ser superada. Aí, as noções racistas acerca da realidade nacional devem ser demolidas. Não é fácil. Algumas estão cristalizadas em forma de consenso e crença. Quem enfrenta crença enfrenta encrenca. A arte é a melhor maneira de se caçar fantasmas, ideal para colocá-los a nu de seus disfarces (CUTI, 2017, p.209).

Não é suficiente que os livros que abordam a história do negro façam parte dos planos de aula no ensino fundamental. É preciso que a leitura orientada e a discussão tenham espaço na escola, de modo a fazer a obra revelar-se em meio a seus temas.

A seguir, analisa-se um caso específico de uma obra clássica da literatura brasileira que expõe as profundas raízes do racismo e permite compreender algumas das condições históricas de sua produção. Toma-se O Mulato, de Aluísio Azevedo, como exemplo de uma obra que, sem dúvida, precisa estar presente no currículo para a reflexão acerca do racismo e do negro, mas que depende, para isso, de ser discutido com a profundidade que a obra requer. 


\section{O racismo brasileiro e a literatura do século xix: análise de o mulato}

A literatura enquanto documento histórico possibilita pensar sobre o racismo no Brasil. Aluísio Azevedo, com a obra O Mulato (1881), é um dos exemplos literários na segunda metade do século XIX. Romance naturalista de grande clamor social, contribuiu para a calcificação da memória histórica sobre o negro brasileiro. A precisão do autor, com a descrição do ambiente em seus mínimos detalhes, dos personagens, das cenas narradas e do desenvolvimento dos enredos, cria a imaginação de um destino de acordo com as "leis naturais", que correspondem ao estilo da literatura do realismo-naturalismo e o racismo científico da época:

[...] movimento que se inicia na segunda metade do século XIX com a retomada do nacionalismo e se estende até o início do século XX. Sua principal característica é a tentativa de traduzir a realidade. [...] é o reflexo da desilusão do homem frente à sociedade: miséria das cidades, crise da produção no campo e péssimas condições de vida. É nesse ambiente que os artistas passavam a observar e a externar a verdade possível da realidade, colocando-se contra o tradicionalismo romântico e procurando incorporar os descobrimentos científicos de seu tempo (MARTINS; LEDO, 2001, p.66).

O estilo da escrita de Alúsio Azevedo na obra O Mulato (1881) apresenta técnicas de como trazer o leitor para a cena. A obra não é escrita apenas para expor uma trama romântica, mas também para fazer variadas denúncias sociais, como, por exemplo, a violência contra a mulher, o machismo e a reflexão sobre o racismo: "Os realistas do século XIX (tanto românticos quanto naturalistas) levaram ao máximo esse povoamento do espaço literário pelo pormenor, - isto é, uma técnica de convencer pelo exterior, pela aproximação com o aspecto da realidade observada." (CANDIDO, 2009, p.79 apud SARAÇOL, 2017, p.38).

O Mulato (1881), mesmo sendo uma obra escrita no período da escravidão negra no Brasil (1530 a 1888), não traz nenhum elemento que expressa a luta pelo fim da escravidão, fenômeno social que estava em 
ascensão no final do século XIX tanto pelas revoltas negras, como pela questão mercadológica estrutural. A reflexão crítica fica a cargo do leitor.

Um ponto interessante sobre a publicação da obra é que existem duas versões: uma publicada em 1881 e a outro em 1889. A mudança entre as duas versões no decorrer dos oito anos expõe o interesse de discutir a escravidão. O enredo continua o mesmo, porém o autor muda algumas colocações gramaticais, como vocabulário, pontuação e algumas frases, como pontua Ferreira $(2011$, p.126):

Oito anos que dividem a publicação das duas edições; anos de profunda transformação no Brasil de então. Intensifica-se na narrativa da segunda edição a presença de assuntos ligados à escravidão; atenua-se a crítica, a religião e a profissão de fé do autor à filosofia positivista.

Com tal característica, a obra a ser aqui analisada será a versão de 1881, pois o objetivo é observar como Aluísio Azevedo pôde revelar, mesmo que sutilmente, os aspectos das relações raciais ao longo da primeira versão publicada.

O Mulato (1881) se passa em São Luiz do Maranhão antes da abolição da escravidão em 1888. A obra inicia com a descrição do ambiente pelo narrador heterodiegético onisciente intruso (ARIELLO, 2008). Além dos pontos da cidade, também descreve o clima quente e as pessoas que estavam ao redor. Ao descrever o espaço, pontua sempre a presença de negros na rua e a diferença entre estes e os brancos na cidade; como os negros viviam, suas características físicas e como os outros os viam. O termo "preta velha", "mulata gorda" e a situação de sujeira em que os negros viviam são sempre destacados. São mencionadas situações em que "negros e moleques" estão sendo vendidos e compara essa ação à venda de animais. Mulheres negras são retratadas frequentemente como vulgares e as partes de seus corpos, descritas sempre relacionadas ao tamanho.

Os traços do corpo negro e as suas atitudes estão sempre relacionadas à animalidade e ao primitivismo (LIMA, 2016). Ao descrever as mulheres, elas são postas em paralelo, brancas e negras. Brancas como sonhadoras e românticas e negras como sujas e vulgares. Traços negros são 
descritos como "beiços enormes" e comportamentos, como "levado dos diabos." Os donos de escravos descrevendo-os como preguiçosos e desobedientes.

O primeiro diálogo da obra é entre Manoel Pescada, um viúvo comerciante português, com sua filha, Anna Rosa. Manoel Pescada deseja que sua filha se case logo e já tem um pretendente para ela. Anna Rosa pontua que, como havia prometido a sua mãe, ela apenas se casaria se amasse alguém e que não casaria para depois amar. Raymundo - o mulato nas primeiras páginas do livro, é apenas mencionado por terceiros. A introdução do ambiente, dos personagens da trama e suas opiniões antecedem a apresentação própria do personagem.

Os personagens apresentados na obra são, em sua grande maioria, descritos como cristãos. Um dos personagens secundários mais presente é o cônego Diogo. O narrador deixa evidente suas práticas criminosas e desonestas, como práticas racistas, assassinatos e o não cumprimento com as normas da igreja. É mencionado que a dona de escravos obrigava-os a rezar todas as noites, todos juntos, às vezes de braços abertos e às vezes algemados.

Raymundo e sua origem familiar entram no diálogo assim que é chegada a notícia de que ele estava voltando ao Maranhão, com a hospedagem na casa do irmão de seu pai - Manoel Pescada - para resolver pendências relacionadas à terra que havia herdado. Era mencionado nos diálogos que Raymundo não era legítimo da família, colocando a questão de que era filho de Domingas, uma escrava, com um senhor branco, José Da Silva, que se enriqueceu com o contrabando de escravos.

É descrito na obra que Domingas havia se submetido a abortos em outras gestações antecedentes a de Raymundo. Isso deixa claro que José Da Silva mantinha relações sexuais com Domingas cotidianamente. Tendo em vista a situação das mulheres negras escravizadas, também se sabe que sofriam diversos abusos, serviam como mucamas, escravas de ganho, que realizavam trabalhos de cunho mais domésticos, trabalhadoras das lavouras, entre outras. Quanto às escravas que viviam nas senzalas, nos centros 
urbanos ou na casa-grande, além de sofrerem abusos diários, também eram estupradas pelos senhores.

Após o nascimento de Raymundo, Domingas recebeu a carta de alforria e ela e o filho foram viver em uma terra de José Da Silva. No entanto, Quitéria - mulher de José Da Silva - "[...] para quem um escravo não era um homem, e ter a cor negra constituía por si só um crime" (AZEVEDO, 1881, p. 35), ressentida ao perceber que seu marido tinha um apreço diferente pelo filho de Domingas, desconfiada sobre a relação do marido com a escrava, vai até Domingas e a tortura na frente de Raymundo, que tinha apenas três anos de idade. Quem ajudou Quitéria a torturar Domingas (raspando seus cabelos, sob chibatadas e queimaduras) foram dois escravos, a mando da senhora.

Raymundo foi levado por José Da Silva para a casa do irmão para ser cuidado e depois levado para Lisboa. Quando volta para o Maranhão, formado em Direito, Raymundo é descrito como um homem que tinha olhos azuis, fazendo questão de mencionar que os olhos ele havia herdado de seu pai, mesmo tendo a pele "amulatada":

\begin{abstract}
Raymundo era um bonito rapaz de vinte e seis annos, um typo verdadeiramente brasileiro si não fossem os grandes olhos azues, que puxara ao pae, tinha os cabellos muito pretos, lustrosos e crespos, a tez morena, um pouco amulatada, porem pallida e fina, os dentes claros, que mais sobresahiam na negrura indiana do bigode, tinha a estatura alta e elegante, o pescoço largo, o nariz direito e a fronte espaçosa. Porem o qué mais impressionava de sua physionomia, o que mais se prendia e fixava na memória de quem o observasse; eram seus grandes olhos azues e sombrios, com o pupilla muito negra e cercados em forma de amêndoa pelas pestanas crespas; as palpebras, estornadas de violeta, tinham uma expressão, sensual de tristeza e ternura; as sobrancelhas, muito desenhadas no rosto, como a nankim, faziam sobresahira frescura da epiderme; a barba, toda raspada, com um colorido azulado, dava ao rosto os tons sympathicos de uma aguarella sobre papel de arroz (AZEVEDO, 1881, p.50-51).
\end{abstract}

Raymundo é descrito como um homem de gestos delicados, culto, que amava arte, ciência e literatura e que falava, além do português, outras línguas, que aprendeu no tempo em que viveu pela Europa. Assim, a miscigenação de Raymundo é vista como uma sorte. Sobre a vida de 
Raymundo em Lisboa é exposto que no ambiente escolar havia sofrido racismo e era deixado sozinho pelos colegas de classe, mesmo frequentando uma escola em que as pessoas tinham um poder aquisitivo equivalente ao dele. Mesmo assim, ele foi deixado sozinho e foi apelidado como "macaquinho" pelos colegas de classe. Diante das poucas memórias que tinha da infância no Brasil - de sua origem e família - Raymundo investe em seus estudos e, como pontua o narrador, Raymundo tenta ser uma pessoa alegre.

Seus anseios giravam em torno da sua pouco memória da infância no Brasil e das poucas informações que tinha sobre ela. Raymundo não tinha lembranças de sua mãe, apenas de seu pai, com quem teve pouco contato até os cinco anos. Todavia, essas lembranças o deixavam confuso porque ele sentia que aquela relação com o pai antes deste ir embora e antes de falecer era uma relação de culpa, que os abraços de que ele se lembrava ter recebido do pai eram carregados de ressentimento e proibição:

E Raymundo recordava-se até que o contacto das barbas de José tinha nessa occasião uma humidade aborrecida, que agora attribuia as lágrimas, depois foi deitar-se e não pensou mais no homem das barbas. Recordava-se também da moléstia de José, dos beijos e abraços que este lhe dava soluçando. E o veu mysterioso de todas estas reminiscencias envolvia-lhe o coração de um modo vago, perplexo triste - sentia um desejo muito seu de abraçar (AZEVEDO, 1881, p. 80).

Em relação a sua mãe, Raymundo não se lembrava de nada. A lembrança afetiva que Raymundo descreve é com a tia, Mariana, esposa de Manoel Pescada, cujos cuidados ele se recordava de ter recebido até os cinco anos de idade.

Raymundo passa por uma série de questionamentos que causam aflição. Questionamentos que dizem respeito a não conhecer o seu passado, que é mantido em segredo pela família de seu pai, para que ele não descobrisse que era filho de uma escrava com um senhor, sendo, assim, um "mulato". Mulato é um termo racista, referindo-se a um cruzamento entre um cavalo e um jumento, ou seja, o europeu sendo o cavalo (puro, bonito, inteligente) e o jumento (animalesco, feio, burro), o negro. Desse "cruzando" 
daria o mulato, uma mistura que não teria como dar certo, o que correspondia à ciência da época que estava propondo a eugenia no Brasil:

\begin{abstract}
Quando essas teorias desembarcaram no Brasil, em fins do século XIX, o país ainda era escravista, com forte presença de traços típicos de uma ex-colônia, com economia débil e dependente - baseada em monocultura, latifúndio e exportação de bens primários -, politicamente desestruturado e com infraestrutura urbana deficiente. Em meio a um contexto histórico tão diferente, era preciso saber como aplicar à realidade nacional doutrinas tidas como científicas e vindas do "continente do progresso". Foi a diminuta classe intelectual do país que tomou para si a responsabilidade de adequar essas doutrinas ao Brasil (TAMANO, 2011, p. 759).
\end{abstract}

Raymundo, por ser um mestiço, é um acontecimento na família e na cidade pois, como disse Cônego Diogo: "[...] ninguém por aqui ignora quem foi a mãe..." (AZEVEDO, 1881, p.29). Aqui são oportunos os apontamentos de Bicudo (2010) acerca da condição psíquica do negro no imaginário nacional já no século XX. O autor traz relatos de negros e "mulatos", pobres e de classe média, e reflete sobre seus sofrimentos ligados às questões raciais. O mestiço brasileiro, por exemplo, considerando a maneira como a abolição foi feita e a relação entre negros e brancos, seria mais bem aceito do que os pretos, mas sem poder representar o que é ser preto, nem o que é ser branco. Ele viveria numa espécie de váculo social, nunca sendo aceito como um branco, embora vivendo em sofrimento na busca de aceitação entre brancos:

[...] em consequência de estar ligado biologicamente e socialmente aos dois grupos raciais esbatidos os traços físicos da raça dominante, ao mesmo tempo em que apresenta traços negróides, o híbrido teria o conflito mental exacerbado. Por um lado, é mais intenso o processo de identificação com o branco, tendo mais oportunidades para se aproximar do branco do que o preto; mas, por outro lado, as marcas raciais podem desenvolver a rejeição social do branco. (BICUDO, 2010, p.109-110).

Raymundo, que se hospeda na casa do tio, Manoel Pescada, conhece Anna Rosa e se apaixona por ela. Raymundo viaja com a finalidade de vender suas terras e conhecer mais sobre si. Manoel o acompanha para ajudá-lo. Eles vão para São Braz, fazenda em que Raymundo nasceu. Ele decide pedir a mão de Anna Rosa para Manoel 
Pescada, porém, todas as vezes que entrava no assunto, Manoel diretamente lhe negava o pedido, o que deixava Raymundo intrigado, pois não havia nenhum motivo aparente sobre a razão de o pai de Anna Rosa não permitir o casamento, afinal, Raymundo era um ótimo homem, segundo os requisitos da época. Com a recusa de Manoel, Raymundo fica ainda mais disposto a se casar com Anna Rosa:

E Raymundo, sem saber porque, sentia-se muito mais empenhado naquelle casamento - desejava-o muito mais depois da resistência que encontrara - aquella recusa vinha dar-lhe a medida do verdadeiro apreço em que tinha Anna Rosa - sentia-a mais desejável, mais encarecida. [...] estava se desconhecendo, espantava-se com os próprios raciocínios como se fossem apresentados por outro, chegava às vezes a não comprehendê-los bem e fugir de estudá-los, com medo de chegar à conclusão de que amava muito Anna Rosa. [...] com esta resolução vinham-lhe novamente ao espirito, de um modo mais claro e positivo, uma grande admiração pelos encantos de Anna Rosa e um pezar dissimulado de não a poder possuir (AZEVEDO, 1881, p.297-2980).

Ao conhecer a fazenda São Braz, ele descobriu que é filho ilegítimo de José Da Silva e se questiona ainda mais sobre quem era sua mãe. Enquanto conhecia o lugar, encontrou uma mulher negra que olhava para ele. Raymundo se assusta e fica parado. Irritado com a maneira como a mulher agia com ele - rindo e se encostando no corpo de Raymundo - ele se irrita e começa a empurrá-la. Nada disso afasta a mulher que ele chama o tempo todo de "diabo" e "peste". Logo, com a insistência, Raymundo começa a Ihe bater, empurrando-a e lhe dando chicotadas. Manoel, ao avistar o que ocorria, pede para ele parar. Raymundo pergunta quem é "essa preta", Manoel apenas responde que ela foi uma escrava do pai de Raymundo.

No meio de tantas dúvidas, Raymundo se pergunta se Manoel é contra o casamento porque ele e Anna Rosa são irmãos, ou se Anna Rosa tem alguma condição médica, Manoel lhe responde:

Não! não! ao contrario, senhor Raymundo - eu levaria muito em gosto o seu casamento com minha filha, no caso que isso si pudesse realizar! E só peço a Deus que Ihe depare um marido, possuidor de suas boas qualidades e de seu saber, porém creia que eu, como bom pae, não devo, de forma alguma, consentir na sua união com Annica - commetteria um crime si assim procedesse!... (AZEVEDO, 1881, p.321). 
Após muita insistência, Manoel conta que não permite o casamento porque Raymundo é mulato, e que, mesmo sendo um ótimo partido e achar "[...] uma asneira! concordo que seja um prejuízo tolo! mas o senhor não imagina a prevenção que há por cá com este negocio de côr!" (AZEVEDO, 1881, p.322). Mesmo Manoel tendo em mente que Raymundo é um rapaz "digno", ele jamais cometeria esse "crime", que seria permitir o nascimento de "descendentes" da união entre Raymundo e Anna Rosa: "[...] o senhor é filho de uma escrava e nasceu também escravo!" (AZEVEDO, 1881, p.322), termina Manoel. Raymundo, então, pergunta qual teria sido o destino de sua mãe. Manoel responde: "[...] soube há pouco que ainda vive - é aquella pobre idiota de S. Braz" (AZEVEDO, 1881, p.323), referindo-se à mulher que Raymundo encontrara mais cedo.

Raymundo se sente desolado com a descoberta. Começa a recordar sua vivência e situações em que ele não entendia por que o tratavam de tal modo: "[...] um mulato! um mulato, que ninguém quer em casa, um ente detestado, um homem, a quem não vale a boa educação, o bom caracter, a illustração, a moral e a delicadeza!" (AZEVEDO, 1881, p.326, grifo do autor).

Ressentido e magoado, Raymundo decide voltar para o Rio de Janeiro. Conta a decisão para Anna Rosa e chegam à conclusão de que juntos irão fugir. Luís Dias, pretendente de Anna Rosa, ao descobrir o plano, conta para Cônego Diogo, que arma uma emboscada para Raymundo. Dias mata Raymundo com um tiro, usando uma arma emprestada pelo Cônego Diogo. Anna Rosa, que estava grávida de Raymundo, após vê-lo morto, sofre um aborto. A obra termina anos à frente do ocorrido, em meio às circunstâncias de Anna Rosa, que se encontra casada com Luís Dias, aparentemente feliz, como descreve o narrador.

\section{Memória histórica brasileira sobre o negro}

Obras como O Mulato são encontradas facilmente nas bibliotecas, nas universidades, nas escolas. Tendo em vista que a literatura é um dos meios 
de representatividade de sujeitos, em O Mulato (1881) pode-se observar um cunho denunciativo, tendo em vista o período em que foi escrita. Entre as várias interpretações que a obra é capaz de provocar na recepção, ela pode servir como um documento para suscitar uma discussão sobre racismo. Proença Filho (2004), ao traçar a trajetória do negro na literatura brasileira, aponta alguns padrões de personagens retratados nas obras literárias brasileiras do século XIX, sendo na sua maioria mulatos que estão sempre em estado de grande sofrimento psíquico. O autor reflete sobre como esta maneira de retratar o negro como sujeito que está sempre em conflito, em intenso processo de exclusão e infelicidade, caracteriza um modo de escrita a fim de atingir a sensibilidade branca, mas que não deixa de portar contradições:

Essa poetização da figura do negro, mais configurada nas manifestações literárias do século XIX, culminou por tornar-se, segundo penso, uma faca de dois gumes: se, como quer ainda o mesmo Antonio Candido, conseguiu impor a dignidade humana do negro, por outro lado passou a ser uma via de saída confortável para o preconceito presente na realidade brasileira, na medida em que acabou escoando na aceitação do negro e do mestiço de negro reconhecido como tal enquanto emocionalmente e socialmente bem comportados, dóceis, resignados e que, como Isaura, sabem reconhecer o lugar que socialmente Ihes foi imposto (PROENÇA FILHO, 2004, p.174)

Trazendo esses elementos para pensar O Mulato (1881), é interessante observar que Raymundo, ao descobrir que é filho de uma escrava, questiona seu valor enquanto sujeito, questiona o valor de ter estudo, ser educado e gentil, sendo filho de uma escrava. A "condição" de Raymundo enquanto mestiço nunca será apenas a de um mestiço: sua vida será limitada e terá um fim trágico, sendo assassinado, enquanto Anna Rosa viverá feliz e casada. Seguindo as "leis naturais", o mestiço estará fadado ao fracasso, à infelicidade e à morte, enquanto a moça branca estará casada com um outro branco e feliz. De certa forma há aí uma visão resignada sobre o futuro do negro nesta sociedade.

Em uma pesquisa com alunos do terceiro ano do ensino médio no interior do Mato Grosso do Sul, João Martos Rosa (2013) usou a obra O 
Mulato (1889) com o objetivo de fazer uma análise sobre quais representações os alunos e alunas fariam sobre a obra. A pesquisa apontou que os estudantes negros, após lerem a obra, não se identificaram com os personagens negros e suas situações. A interpretação mais comum foi a de que o fim mal-sucedido do protagonista tem a ver com ser negro, o que significa ser fadado ao fracasso. Rosa (2013) descreve que o discurso dos alunos oscilou entre o mito da democracia racial e a culpabilização do próprio negro pelo rumo de sua vida e o racismo sofrido. Todavia, também pôde-se observar que alguns dos alunos identificaram que a cultura brasileira, por via dos meios midiáticos, perfaz uma representação racista do negro, dificultando que negros possam se ver como negros, com um olhar positivo sobre si e sobre seu futuro:

O negro brasileiro não pode ser tratado como o outro, que tanto trabalhou pela grandeza da nação etc. e a quem se deve reconhecimento especial por isso, como não cabe agradecer aos brancos portugueses ou aos índios, mas também não deve tratar-se como o outro em nome de sua auto-afirmação. Como os demais grupos étnicos, ele é parte da comunidade que fez e faz o país. Se a luta em que se empenha se tornou e continua necessária, isto se deve, como é sabido, ao fato de ter-se tornado alvo de tratamento social e historicamente discriminatório (PROENÇA FILHO, 2004, p.186).

A literatura possibilita pensar sobre as representações sociais e singulares no imaginário dos sujeitos e ela tem apresentado o negro sempre enfrentando as vicissitudes que advêm do racismo. Na sutileza de mostrar o negro enquanto puro sofrimento, não importa o que ele faça, as obras literárias dialogam com o racismo velado. A literatura por si só pode suscitar diversas discussões. Portanto, ao levar uma obra literária para a escola, não basta apenas haver uma recomendação de leitura aos alunos, mas é necessário que haja um aprofundamento nas questões que o livro traz. Essas discussões são importantes, pois elas podem ajudar os estudantes a compreender questões de sua subjetividade e cultura. É importante que, para isso acontecer, a escola esteja disposta a trabalhar as diversas questões complexas do Brasil, como o racismo, sob pena de obras literárias como 0 
mulato terem uma recepção empobrecida e aquém da crítica aguda que ela carrega consigo.

Ao longo dos anos, a literatura foi se modificando e as representações sociais do negro têm se ampliado. Desde o século XX, como aponta Proença Filho (2004), tem havido uma ascensão de autores negros com outros estilos de narrativas que possibilitam traçar rumos positivos sobre os negros brasileiros. Porém, há ainda muito a se fazer, como pensar na acessibilidade dessas obras para os estudantes nas escolas, e não serem apenas obras escondidas e esquecidas. Como aponta Proença Filho (2004, p.190): "O caminho vem sendo percorrido".

\section{Considerações finais}

Buscou-se aqui discutir a abrangência do racismo no Brasil e uma maneira de combatê-lo por meio do estudo e do debate da cultura negra nas escolas, especificamente por meio da literatura. Os apontamentos apresentados procuraram evidenciar que a literatura pode não apenas mostrar como o racismo tem origens longínquas no Brasil, sendo crítico a ele, como propiciar um âmbito de experiências capazes de contribuir para o fortalecimento da identidade do negro e, ao mesmo tempo, para a identificação do branco com a alteridade, o que, no horizonte teórico, são aspectos que podem fortalecer a frágil democracia brasileira.

Não se pode ter a ilusão, no entanto, de que a educação seja capaz de transformar o mundo: as diversas formas de violência, entre elas o preconceito, possuem fortes relações com um sistema econômico que gera constante insegurança a todos, impede a autossuficiência e ensina a ver no próximo apenas um concorrente, que deve, sempre que possível, ser vilipendiado.

Enquanto as condições objetivas irracionais persistem, é importante a luta pelo fortalecimento da consciência para resistir a um mundo em que a barbárie sempre bate à porta. Nesse sentido, a literatura é não apenas uma importante expressão da realidade destinada às consciências humanas, 
como também um antídoto contra a barbárie, já que propicia uma experiência transformadora no contato com a alteridade.

\section{Referências}

ADORNO, Theodor Wiesengrund. Teoria estética. Lisboa: Edições 70, 1970.

ADORNO, Theodor Wiesengrund. Educação após Auschwitz. In: Educação e emancipação. Rio de Janeiro: Paz e Terra, 2000.

ALMEIDA, Rogério de. Educação Contemporânea: a sociedade autolimpante, o sujeito obsoleto e a aposta na escolha. EDUCAÇÃO: Teoria e Prática, v. 20, n.34, p.47-64, jan/ jun., 2010. Disponível em:

https://www.researchgate.net/publication/277766334_Educacao_Contempo ranea a sociedade autolimpante o sujeito obsoleto e a aposta na escol ha. Acesso em 24 de set. de 2018.

ARIELLO, Fabiane Marina Amend. O narrador plural: a voz narrativa em The Jane Austen Book Club, de Karen Joy Fowler. Monografia de final de curso. Letras. U.F. Paraná. 2008. Disponível em:

http://www.letras.ufpr.br/documentos/graduacao/monografias/ss 2008/Fabi ane_Arielo.pdf. Acesso em 03 jan. 2019.

AZEVEDO, Aluísio. O Mulato. 1 ed. Maranhão: Typ. do Paiz, 1881. Disponível em: https://digital.bbm.usp.br/handle/bbm/4812. Acesso em 10 ago. 2018.

BICUDO, Virginia Leone. Atitudes raciais de pretos e mulatos em São Paulo. Edição organizada por Marcos Chor Maio. São Paulo: Editora Sociologia e Política, 2010, 192 pp.

BONFIM, Vania Maria. A identidade contraditória da mulher negra brasileira: bases históricas. In: LARKIN, Elisa. (Org.) Afrocentricidade: uma abordagem epistemológica inovadora. São Paulo: Selo Negro, 2009, p. 219-249.

BRASIL. Casa Civil. Lei 10.639, de 09 de janeiro de 2003. Diário Oficial da República Federativa do Brasil. Poder Executivo, Brasília, DF, 2003. Disponível em: <http://www.planalto.gov.br/ccivil_03/leis/2003/l10.639.htm>. Acesso em: 22 out. 2018.

CUTI (Luiz Silva). Quem tem medo da palavra negro. In: KON, Noemi Moritz; SILVA, Maria Lúcia; ABUD, Cristiane Curi. (Orgs.) O racismo e o negro no Brasil: questões para a psicanálise. São Paulo: Perspectiva, 2017.

FERREIRA, Cassio Dandoro Castilho. O mulato, de Aluísio Azevedo: um romance, duas versões (1881-1889). 2011. 453 f. Dissertação (Mestrado em Letras) - Universidade Federal do Paraná, Curitiba, 2011. 
FERREIRA-SANTOS, Marcos; ALMEIDA, Rogério. Antropolíticas da educação. 2 ed. São Paulo: Képos, 2014.

FÉTIZON, Beatriz. Sombra e luz: o tempo habitado. São Paulo: Zouk, 2002.

FINCH III, Charles S.; LARKIN, Elisa. Abordagem afrocentrada, história e evolução. In: LARKIN, Elisa. (Org.) Afrocentricidade: uma abordagem epistemológica inovadora. São Paulo: Selo Negro, 2009, p. 219-249.

FLEITH, Denise de Souza. A política nacional de educação especial na perspectiva da educação inclusiva. In GUZZO, R. S. L.; MARINHO-ARAÚJO, C. M. (Orgs.) Psicologia escolar: identificando e superando barreiras. Campinas: Ed. Alínea, 2011.

FOUCAULT, Michel. Vigiar e punir: nascimento da prisão. 27 ed. Petrópolis: Vozes, 1987. 288 pp.

FREUD, Sigmund. O eu e o id. In: Obras completas. Volume 16. Trad. Paulo César de Souza. São Paulo: Companhia das Letras, 201 1. (Texto publicado pela primeira vez em 1923).

HILLIARD III, Asa Grant. O rabequista e a festa: uma crítica africana à educação multicultural nos Estados Unidos. In: LARKIN, Elisa. (Org.)

Afrocentricidade: uma abordagem epistemológica inovadora. São Paulo: Selo Negro, 2009, p. 315-329.

IBGE. IBGE mostra as cores da desigualdade. 2018. Disponível em: https://agenciadenoticias.ibge.gov.br/agencia-noticias/2012-agencia-denoticias/noticias/21206-ibge-mostra-as-cores-da-desigualdade. Acesso em 20 dez. 2018.

LARKIN, Elisa. (Org.) Afrocentricidade: uma abordagem epistemológica inovadora. São Paulo: Selo Negro, 2009.

LIMA, Bruna Della Torre de Carvalho. Eles devoraram tudo: primitivismo, barbárie e as vanguardas. Revista do Instituto de Estudos Brasileiros [online]. 2016, n. 64, p. 296-309. Disponível em: http://dx.doi.org/10.11606/issn.2316901X.v0i64p296-309. Acesso em 03 de jan. 2019.

MARTINS, Patrícia; LEDO, Terezinha de Oliveira. Manual de literatura: literatura portuguesa, literatura brasileira. São Paulo: DCL, 2001.

MIGNOLO, Walter. Aiesthesis Decolonial: articulo de reflexión. Revista Calle 14, 2010, v. 04, n. 04, p. 11-25. Disponível em: http://revistas.udistrital.edu.co/ojs/index.php/cl 4/article/view/1224/1635 Acesso em 19 set. 2018. 
NASCIMENTO, Abdias do. Drama para negro, prólogos para brancos. Rio de Janeiro: Edição do Teatro Experimental do Negro, 1961.

NASCIMENTO, Abdias do. O genocídio do negro brasileiro: processo de um racismo mascarado. reimpr. da 2 ed. São Paulo: Perspectiva, 2017.

NOBLES, Wade. Sakhu Seti: retomando e reapropriando um foco psicológico afrocentrado. In: LARKIN, Elisa. (Org.) Afrocentricidade: uma abordagem epistemológica inovadora. São Paulo: Selo Negro, 2009, p. 219-249.

NOGUERA, Renato. Afrocentricidade e educação: os princípios gerais para um currículo afrocentrado. Revista África e Africanidades, Ano 3, n 11 , novembro, 2010. Disponível em:

http://www.africaeafricanidades.com.br/documentos/01112010_02.pdf. Acesso em 20 nov. 2018.

NOGUERA, Renato. O ensino de filosofia e a lei 10.639. Rio de Janeiro: Pallas; Biblioteca Nacional, 2014.

PROENÇA FILHO, Domício. A trajetória do negro na literatura brasileira.

Estudos Avançados, São Paulo, v.18, n. 50, p. 161-193, abr. 2004. Disponível em: http://www.scielo.br/scielo.php?script=sci_arttext\&pid=S010340142004000100017\&lng=en\&nrm=iso. Acesso em 04 jan. 2018.

RIBEIRO, Katiúscia Pontes. Kemet, escolas e arcádeas: a importância da filosofia africana no combate ao racismo epistêmico e a lei 10639/03. Dissertação. (Mestrado em filosofia) - Centro Federal de Educação Tecnológica Celso Suckow da Fonseca, 2017, 93 p.

ROSA, João Martos. Representações de negros produzidas por alunos, mediadas pela leitura da obra "O Mulato". Dissertação (Mestrado em Educação) - Universidade Católica de Brasília, 2013.

SANTOS, Antônio Bispo. Colonização, quilombos: modos e significados. Brasília: Editora Universidade Federal de Brasília, 2015.

SANTOS, Neuza. Tornar-se negro: as vicissitudes do negro brasileiro em ascensão social. Vol 4. Rio de Janeiro: Edições Graal, 1983.

SARAÇOL, Helena Fleck. A escravidão e seus vestígios retratados nos romances maranhenses do século XIX: uma análise das obras $O$ mulato, de Aluísio de Azevedo e Ursula, de Maria Firmina dos Reis. Trabalho de Conclusão (Licenciatura em Letras-Português e Literaturas de Língua Portuguesa.) - UNIPAMPA, 2017. 
TAMANO, Luana Tieko Omena (et al.) O cientificismo das teorias raciais em $O$ cortiço e Canaã. História, Ciências, Saúde - Manguinhos, Rio de Janeiro, v. 18, n. 3, jul.-set. 2011, p. 757-773. Disponível em:

http://www.scielo.br/pdf/hcsm/v18n3/09.pdf Acesso em 22 set. 2018.

Recebido em: 15 de fevereiro de 2020

Aprovado em: 07 de junho de 2020

Publicado em: 29 de agosto de 2020

(c). (i) (8) 